7 Hanson L, Danis M, Garrett J, Mutran E. Who decides? Physicians' willingness to use life-sustaining treatment. Arch Intern Med 1996;156:785-9.

8 Wachter R, Luce J, Hearst N, Lo B. Decisions about resuscitation: inequities among patients with different diseases but similar prognoses. Ann Intern Med 1989;111:525-32.

9 Tanvetyanon T, Leighton J. Life-sustaining treatments in patients who died of chronic congestive heart failure compared with metastatic cancer. Crit Care Med 2003;31:60-4.

10 Claessens MT, Lynn J, Zhong Z, Desbiens NA, Phillips RS, Wu AW, et al. Dying with lung cancer or chronic obstructive pulmonary disease: insights from SUPPORT study (Study to Understand Prognoses and Preferences for Outcomes and Risks of Treatments). I Am Geriatr Soc 2000;48:S146-53.

11 Tarnow-Mordi WO, Hau C, Warden A, Shearer AJ. Hospital mortality in relation to staff workload: a 4 -year study in an adult intensive care unit Lancet 2000;356:185-9.
12 Suhl J, Simons P, Reedy T, Garrick T. Myth of substituted judgment. Surrogate decision making regarding life support is unreliable. Arch Intern Med 1994:154:90-6.

13 Coppola KM, Ditto PH, Danks JH, Smucker WD. Accuracy of primary care and hospital-based physicians' predictions of elderly outpatients treatment preferences with and without advance directives. Arch Intern Med 2001;161:431-40.

14 Ely JW, Peters PG Jr, Zweig S, Elder N, Schneider FD. The physician's decision to use tube feedings: the role of the family, the living will, and the Cruzan decision. J Am Geriatr Soc 1992;40:471-5.

15 Azoulay E, Chevret S, Leleu G, Pochard F, Barboteu M, Adrie C, et al. Half the families of intensive care unit patients experience inadequate communication with physicians. Crit Care Med 2000;28:3044-9.

(Accepted 16 June 2004)

\title{
Effects of reduction in heroin supply on injecting drug use: analysis of data from needle and syringe programmes
}

\author{
Carolyn Day, Louisa Degenhardt, Stuart Gilmour, Wayne Hall
}

National Drug and Alcohol Research Centre, University of New South Wales, Sydney, NSW 2052,

Australia

Carolyn Day doctoral candidate

Louisa Degenhardt lecturer

Stuart Gilmour statistician

Office of Public Policy and Ethics, Institute for

Molecular

Bioscience,

University of

Queensland, St

Lucia, Brisbane,

OLD 4072,

Australia

Wayne Hall

professor

Correspondence to: C Day carolyn.day@ unsw.edu.au

BMJ 2004;329:428-9
In early 2001 there was a dramatic decline in the availability of heroin in New South Wales (NSW), Australia, where previously heroin had been readily available at a low price and high purity. ${ }^{1}$ The decline was confirmed by Australia's strategic early warning system, which revealed a reduction in heroin supply across Australia and a considerable increase in price, ${ }^{2}$ particularly from January to April 2001.

This "heroin shortage" provided a natural experiment in which to examine the effect of substantial changes in price and availability on injecting drug use and its associated harms in Australia's largest heroin market, ${ }^{2}$ a setting in which harm reduction strategies were widely used. Publicly funded needle and syringe programmes were introduced to Australia in 1987, and methadone maintenance programmes, which were established in the 1970 s, were significantly expanded in 1985 and again in 1999.

\section{Methods and results}

In NSW needle and syringe programmes are delivered primarily within the public sector through area health services. There is also a private sector programme, subsidised by the government, delivered through pharmacies (known as "fitpacks"). This enables injecting drug users to purchase or exchange needles and syringes. We used data collected by these programmes to examine the extent of injecting drug use. These data are representative of all needles and syringes distributed to injecting drug users in NSW and have been combined to produce quarterly comparable data.

The number of needles and syringes distributed in NSW decreased around the onset of the heroin shortage (figure) and the reduction was sustained until the end of the period for which data were available. The number of needles distributed decreased from around 3.1 million per quarter immediately before the heroin shortage to just under 2.2 million in mid-2002-a decrease of around 28\%. Time series analysis on monthly data from major needle and syringe programmes suggested that this decline was not a seasonal effect and was tied closely to the onset of the shortage (analysis available on request).

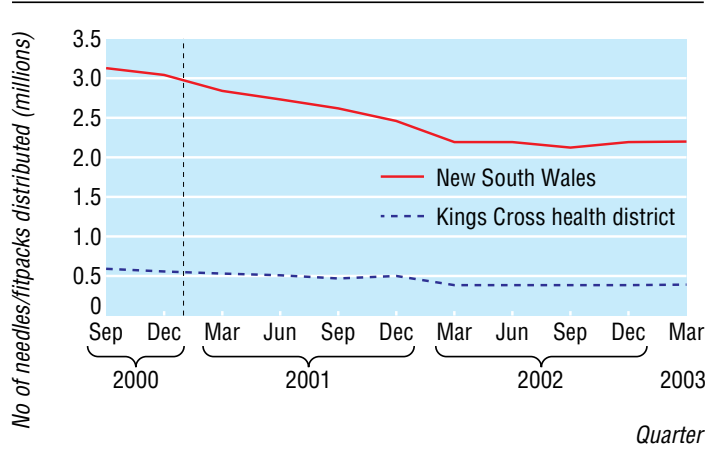

Number of needles distributed in New South Wales, Australia, 2000-3 (data from AIDS and Infectious Diseases Branch, NSW Department of Health)

\section{Comment}

We found a sustained reduction in the number of needles and syringes distributed in NSW after a considerable decrease in heroin supply. Given the widespread and easy availability of needles and syringes in NSW, the data on provision are a useful proxy for changes in the number of injecting drug users or in the frequency of injecting, or both. The trends observed here were also consistent with estimated reductions in the number of regular heroin users after the heroin shortage. ${ }^{3}$ These data suggest an overall reduction in the prevalence of injecting drug use after a decrease in heroin supply.

We relied on secondary data sources as indirect measures of the prevalence of injecting drug use. None the less, the coherent pattern of changes outlined in this study is not easily explained by any other hypotheses and is consistent with other research on the consequences of the heroin shortage. ${ }^{3}$

Our findings are also consistent with a reduction in notifications of hepatitis $\mathrm{C}$ among people aged 15-19 years, which started around the time of the reduction

This article was posted on bmj.com on 3 August 2004: http://bmj.com/ cgi/doi/10.1136/bmj.38201.410255.55 


\section{What is already known on this topic}

The impact of reduced heroin supply on injecting drug use (where this is the drug of choice) has not previously been determined

\section{What this study adds}

Reduced heroin supply is associated with reduced injecting drug use

in heroin supply. ${ }^{4}$ Nearly all such infections are related to injecting drug use, and there are no alternative explanations for the decrease in notifications, which was not predicted by mathematical models of the hepatitis C epidemic in Australia. ${ }^{5}$ However, the true impact of reduced supply is unlikely to be detectable for some time. Reduction in injecting drug use, as indicated by reduced output in the needle and syringe programmes, would be consistent with reduction in such infections at the population level. We are currently exploring further impacts of the shortage on overdose, treatment, and crime.

We thank the many agencies and individuals who provided advice and data for inclusion in the study; Linette Collins, Amy Gibson, and Elizabeth Conroy for assistance with the project; and Owen Westcott and Jenny Iverson from the AIDS and Infectious Diseases Branch of NSW Health for facilitating access to NSW notification and programme data. We also thank Greg Dore, Lisa Maher, and Margaret MacDonald for comments on an earlier draft of the paper.
Contributors: CD (guarantor), LD, and WH conceived the study. LD supervised the research. CD led the writing. SG conducted the analysis for the study. All authors helped to conceptualise ideas, interpret findings, and review drafts of the manuscript.

Funding: This work was completed as part of a larger project funded by the Australian National Drug Law Enforcement Research Fund (NDLERF). The National Drug and Alcohol Research Centre is funded by the Australian Government Department of Health and Ageing. CD was funded by a postgraduate award from the Australian Government Department of Health and Ageing.

Competing interests: None declared.

Ethical approval: The study was approved by the University of New South Wales human research ethics committee and the human research ethics committees of the South Eastern Sydney Area Health Service, South Western Area Health Service, and Central Sydney Area Health Service.

1 Darke S, Topp L, Kave S, Hall W. Heroin use in New South Wales, Australia, 1996-2000: 5 year monitoring of trends in price, purity, availability and use from the illicit drug reporting system (IDRS). availability and use from

2 Topp L, Kaye S, Bruno R, Longo M, Williams P, O'Reilly B, et al. Australian drug trends 2001: findings from the illicit drug reporting system (IDRS). Sydney: National Drug and Alcohol Research Centre, University of New South Wales, 2002.

3 Degenhardt L, Day C, Hall W, eds. The causes, course and consequence of the heroin shortage in Australia. Adelaide: Australasian Centre for Policing Research, 2004.

4 National Centre in HIV Epidemiology and Clinical Research. HIV/AIDS, viral hepatitis and sexually transmissible infections in Australia: anmual suruitviral hepatis 2003 Sydney: National Centre in HIV Epidemiology aitlance report 2003. Sydney. National Centre in HIV Epice

5 Law M, Dore G, Bath N, Thompson S, Crofts N, Dolan K, et al. Modelling hepatitis $\mathrm{C}$ virus incidence, prevalence and long-term sequelae in Australia, 2001. Int J Epidemiol 2003;32:717-24.

(Accepted 23 June 2004)

doi $10.1136 /$ bmj.38201.410255.55

\title{
DRUG POINTS
}

\section{Fatal liver failure associated with pioglitazone}

\author{
Ed Farley-Hills, R Sivasankar, M Martin
}

Thiazolidinediones are peroxisomal proliferator activated receptor $\gamma$ agonists. Troglitazone is associated with idiosyncratic hepatic reaction, liver failure, and death and is withdrawn. ${ }^{12}$ The toxicity of troglitazone is unlikely to be a class effect of thiazolidinediones since rosiglitazone and pioglitazone have shown little evidence of hepatic toxicity. Some patients taking pioglitazone, however, have had liver failure, but no deaths are associated with it. $^{4}$

A 63 year old white man with no history of alcohol misuse was admitted to hospital with jaundice after feeling unwell for three weeks. Three months before, doctors changed his gliclazide to pioglitazone. He had also taken lercanidipine for some years and a cephalosporin antibiotic for a few days. Blood investigations found concentrations of $522 \mu \mathrm{mol} / 1$ bilirubin, 472 IU/l alkaline phosphatase, 1053 IU/1 aspartate aminotransferase, $1984 \mathrm{IU} / \mathrm{l}$ alanine aminotransferase, $455 \mu \mathrm{mol} / \mathrm{l}$ creatinine, and $28 \mathrm{~g} / \mathrm{l}$ albumin. His prothrombin time was 56 seconds. He developed encephalopathy and acidosis 36 hours after admission and doctors transferred him to intensive care.

He had no stigmata of chronic liver disease, and hepatitis surface antigen, hepatitis A IgM, and hepatitis C antibody were negative. Ultrasound images showed normal parenchymal reflectivity with patent vessels and no biliary dilatation. When stabilised, doctors transferred him to the regional liver unit. He died nine days later.

The histopathology report describes parenchymal damage with steatohepatitis including Mallory bodies superimposed on a severely fibrotic liver. The cause is not certain, but the degree of fibrosis suggests a chronic process, and the type of necroinflammatory activity raises the possibility of alcohol related liver injury. Alternatively the changes could be drug induced damage superimposed on chronic liver disease related to diabetes, and the time scale indicates that pioglitazone is the likely cause.

We know of no previous cases of death associated with pioglitazone, although liver failure has been reported.

Funding: None.

Competing interests: None declared.

1 Isley WL. Hepatotoxicity of thiazolidinediones. Expert Opin Drug Saf 2003;2:581-6.

2 Tolman KG, Chandramouli J. Hepatotoxicity of the thiazolidinediones. Clin Liver Dis 2003;7:369-79.

Scheen AJ. Hepatotoxicity with thiazolidinediones: is it a class effect? Drug Saf 2001;24:873-88.

4 Chase MP, Yarze JC. Pioglitazone-associated fulminant hepatic failure. $\mathrm{Am}$ J Gastroenterol 2002;97:502-3. 